\title{
Occupational exposure to formaldehyde and wood dust and nasopharyngeal carcinoma
}

Thomas L Vaughan, Patricia A Stewart, Kay Teschke, Charles F Lynch, G Marie Swanson, Joseph L Lyon, Marianne Berwick

Objectives-To investigate whether occupational exposures to formaldehyde and wood dust increase the risk of nasopharyngeal cancer (NPC). Methods-A multicentred, population based case-control study was carried out at five cancer registries in the United States participating in the National Canbetween 1987 and 1993, and controls $(n=244)$ selected over the same period from the general population through random digit dialing participated in structured telephone interviews which inquired about suspected risk factors for the disease, including a lifetime history of occupational and chemical exposure. Histological type of cancer was abstracted from clinical records of the registries. Potential exposure to formaldehyde and wood dust was assessed on a job by job basis by experienced industrial hygienists who were blinded as to case or control status.

Results-For formaldehyde, after adjusting for cigarette use, race, and other risk factors, a trend of increasing risk of squamous and unspecified epithelial carcinomas was found for increasing duration $(p=0.014)$ and cumulative exposure $(p=0.033)$ but not for maximum exposure concentration. The odds ratio (OR) for people cumulatively exposed to $>1.10$ ppm-years was 3.0 (95\% confidence interval $(95 \%$ CI) 1.3 to 6.6$)$ compared with those considered unexposed. In analyses limited to jobs considered definitely exposed, these trends became stronger. The associations were most evident among cigarette smokers. By contrast, there was no association between potential exposure to formaldehyde and undifferentiated and non-keratinising carcinomas. There was little evidence that exposure to wood dust increased risk of NPC, as modest crude associations essentially disappeared after control for potential exposure to formaldehyde.

Conclusions-These results support the hypothesis that occupational exposure to formaldehyde, but not wood dust, increases risk of NPC. This association seems to be specific to squamous cell carcinomas. Established cohorts of workers exposed to formaldehyde and wood dust should continue to be monitored for NPC and other respiratory cancers. Future studies of NPC should take into account histological type in assessing risk from environmental and host factors. (Occup Environ Med 2000;57:376-384)

Keywords: occupational exposure; formaldehyde; wood dust

The International Agency for Research on Cancer (IARC) recently classified formaldehyde as a probable human carcinogen (group 2A). ${ }^{1}$ This classification was based primarily on experimental evidence in animals; the evidence from human studies is more limited and somewhat inconsistent. Epidemiological studies have focused predominantly on respiratory cancers. Among these, exposure to formaldehyde has been linked most consistently with increased risk of nasopharyngeal cancer (NPC). Positive results have been reported from both cohort ${ }^{23}$ and case-control ${ }^{4-6}$ studies. However, several studies suggesting no association with NPC have also been reported..$^{7-9}$

By contrast with formaldehyde, substantial epidemiological evidence exists linking exposure to wood dust to increased risk of cancer, prompting IARC to classify wood dust as a group 1 carcinogen. ${ }^{1}$ This classification was based primarily on extremely high relative risks of adenocarcinomas of the sinonasal cavities among people occupationally exposed to dust from hardwoods. ${ }^{1{ }^{10} 11}$ More limited evidence suggests an increased risk of squamous cell carcinomas of the sinonasal cavities and the nasopharynx. ${ }^{12-14}$

A chief difficulty in any study of NPC in the United States is its rarity. ${ }^{15}$ Age adjusted annual incidences among white people are 0.5 and 0.2 per 100000 for men and women respectively. ${ }^{16}$ Consequently even the largest cohort studies of workers exposed to formaldehyde have had expected numbers of cases of NPC of two or less, ${ }^{12}$ and the only previously reported interview based case-control study in the United States included 27 cases of NPC. ${ }^{4}$ In an effort to overcome this problem, we conducted a multicentre population based case-control study at five cancer registries in the United States to investigate environmental and genetic risk factors for NPC. In this sixth report from the collaborative study we investigate the role of occupational exposures to formaldehyde and wood dust in the aetiology of nasopharyngeal carcinomas. 
Methods

SUBJECT ASCERTAINMENT

A detailed description of the data collection methods has been published previously. ${ }^{17}$ Briefly, cases of NPC were identified prospectively at five population based cancer registries in the United States participating in the National Cancer Institute's SEER programme. At four registries (Connecticut, metropolitan Detroit, Iowa and Utah), cases diagnosed between 1 April 1987 and 30 June 1991 were included; at the western Washington registry, case ascertainment was extended to 30 June 1993. Eligible cases included men and women between 18 and 74 years of age with any histological type of NPC. Controls were identified by random digit dialing using a modified Waksberg's method, ${ }^{18}$ and frequency matched to the cases by age (in 5 year groups), sex, and cancer registry. By this method, a representative sample of households in a geographic region is identified by the random generation of telephone numbers from lists of working exchanges. ${ }^{17}$ Each number is called up to nine times at different times of the day and week over a period of several weeks to find whether the number identifies a residence. Households identified in this way are then screened for eligible controls.

Overall we identified 294 eligible cases; 105 occurred in Washington, 75 in Detroit, 64 in Connecticut, 36 in Iowa, and 14 in Utah. Of these, interviews were completed for 240 $(82 \%)$. To maintain comparability with controls, nine cases without a telephone at the reference date 1 year before diagnosis were excluded from further analyses. In instances where cases were dead or too ill to participate, interviews were conducted with proxies (usually the spouse). This occurred for $44(19.0 \%)$ of the 231 interviewed and eligible cases.

For the present report, we focused on the 196 cases with epithelial cancers. These were classified according to the World Health Organisation (WHO) scheme into three histological groups with the international classification of diseases - oncology (ICD-O) codes: epithelial NOS $(801 x-804 x)(n=24)$, undifferentiated $(8020,8021,8082)$, or nonkeratinising (8072, 8073) $(\mathrm{n}=54)$, and squamous cell (805x-808x, except 8072, 8073) $(n=118) .{ }^{19}$ Previous reports from this and other studies suggest that the aetiology of undifferentiated and non-keratinising carcinomas of the nasopharynx is likely to be substantially different than other carcinomas arising in this site. ${ }^{17}$ Consequently we excluded these histologies from certain analyses.

In ascertaining controls we successfully screened 2649 (92\%) of 2885 households, from which we identified 324 eligible controls, and successfully interviewed $246(76 \%)$. Two controls without telephones at the reference date 1 year before ascertainment were excluded, leaving 244 for analyses. Three $(1.2 \%)$ control interviews were with proxies.

DATA COLLECTION

Experienced interviewers at each registry conducted structured telephone interviews with cases and controls. All questions referred to the period before the reference date, which was 1 year before diagnosis for cases and 1 year before ascertainment for controls. We collected information on demographic background, previous medical conditions and use of medication, family history of cancer, use of tobacco and alcohol products, and a lifetime history of occupational and chemical exposure.

For each job that a respondent held for at least 6 months, we inquired about the job title, typical activities and duties in the job, the type of industry, and the start and stop dates. In an attempt to ensure complete reporting of jobs that might have entailed exposure to wood dust, formaldehyde, and other exposures of interest, we inquired whether they held a job in 13 specific industries - for example, furniture manufacture, construction, foundry, and smelter. As well as the occupational history, we asked about exposure to specific chemicals or other agents (including wood dust and formaldehyde) to which the respondent may have been exposed. If a subject reported a particular exposure in the workplace, we asked about specific activities associated with the exposure and the particular jobs involved.

\section{EXPOSURE ASSESSMENT}

Estimates of exposures were carried out on a job by job basis for each subject by industrial hygienists with substantial experience in assessment of exposure to formaldehyde $(\mathrm{PAS})^{22021}$ and wood dust $(\mathrm{KT})^{22-24}$ in epidemiological studies. Exposure assessment was carried out in a blinded fashion (without knowledge of case or control status) with the occupational history, which included industry description, job title, and duties, and dates started and stopped, supplemented by any self reported exposure information associated with each job. Estimates were based on published and unpublished literature, as well as personal experience.

Each job held by a subject was assigned a probability of being exposed to formaldehyde as follows: definitely not or unlikely $(<10 \%)$, possible $(\geqslant 10 \%$ and $<50 \%)$, probable $(\geqslant 50 \%$ and $<90 \%)$, and definite $(\geqslant 90 \%) .^{25-28}$ The probability represented the percentage of people with a similar job profile (occupation, industry, dates of employment, etc) expected to be exposed to formaldehyde. Jobs with potential exposure were further assigned an estimated concentration of exposure representing an 8 hour time weighted average (TWA-8): low $(<0.10 \mathrm{ppm})$, moderate $(\geqslant 0.10$ and $<0.50$ $\mathrm{ppm})$, and high ( $\geqslant 0.50 \mathrm{ppm})$. These estimates considered the frequency (days/year) and duration (hours/day) of exposure over the long term. Overall, 2209 jobs were reported by participants, of which $291(13.2 \%)$ were assigned an exposure probability of possible or higher. The distribution of all reported jobs by estimated level and probability of exposure to formaldehyde is given in table 1 . Of the nine jobs possibly involving high exposure, six involved metal foundry work - such as core cleaning or molding. Subjects reported 24 jobs which they considered to entail exposure to 
Table 1 Distribution of estimated concentration and probability of exposure to formaldehyde for jobs reported by all subjects

\begin{tabular}{|c|c|c|c|c|c|}
\hline \multirow[b]{2}{*}{ Probability } & \multicolumn{4}{|c|}{ Exposure (ppm) } & \multirow[b]{2}{*}{ Total } \\
\hline & $\begin{array}{l}\text { None or } \\
\text { minimal }\end{array}$ & $<0.10$ & $0.10-0.50$ & $>0.50$ & \\
\hline Definitely not or unlikely & 1918 & & & & $1918(86.8)$ \\
\hline Possible & & 170 & 15 & 9 & $194(8.8)$ \\
\hline Probable & & 53 & 23 & 0 & $76(3.4)$ \\
\hline Definite & & 17 & 4 & 0 & $21(1.0)$ \\
\hline Total & $1918(86.8)$ & $240(10.9)$ & $42(1.9)$ & $9(0.4)$ & $2209(100.0)$ \\
\hline
\end{tabular}

formaldehyde. Of these, 19 were assigned to the definite exposure category (16 in the low level category and three in moderate), three to probable (all in the low level category) and two to possible (one in the low level category and one in the moderate).

For the assessment of wood dust, a job was selected for evaluation by the industrial hygienist if (a) its occupation code was one of forestry, logging, carpenter, other construction worker, precision wood worker, or wood working machine operator; $(b)$ its industry code was one of construction, paper product manufacturing, lumber, wood product manufacturing, or furniture and fixtures; or $(c)$ the subject self reported occupational exposure to wood dust. Jobs not so selected were coded as unexposed. Selected jobs were assigned a likely total wood dust TWA-8 level as follows: no or minimal exposure $\left(<0.10 \mathrm{mg} / \mathrm{m}^{3}\right)$, low $(\geqslant 0.10$ and $<1.0$ $\left.\mathrm{mg} / \mathrm{m}^{3}\right)$, moderate $\left(\geqslant 1.0\right.$ and $\left.<2.0 \mathrm{mg} / \mathrm{m}^{3}\right)$, and high $\left(\geqslant 2.0 \mathrm{mg} / \mathrm{m}^{3}\right) .{ }^{29-36}$ The frequency and type of dust generating tasks were important considerations in the classifications. The highest exposure level was assigned to jobs involving frequent sanding or milling duties (cabinet makers, furniture makers, pattern makers, boat builders, floor finishers, etc). Those involving frequent sawing, pressboard sawing, sweeping, or intermittent sanding (saw operators, clean up personnel, construction carpenters with some cabinet making duties, etc) were assigned moderate levels. Low exposures were assigned to jobs involving intermittent sawing (construction carpenters, handymen, etc), work generating large particle sizes which settle quickly (loggers), or work in a dusty area but with indirect exposure (sawmill labourers). Exposure to wood dust is more likely to be easily identified and recalled by subjects than exposure to formaldehyde. Most jobs $(75 \%)$ in which the subjects recalled exposure to wood dust were rated by the hygienist as exposed. Few jobs (15\%) in which the subjects did not recall exposure were rated as exposed. Overall, $51(2.3 \%)$ jobs were assigned an exposure of low, $14(0.6 \%)$ as moderate, and $11(0.5 \%)$ as high.

For individual jobs, there was only moderate correlation between the concentrations of formaldehyde and wood dust when each was categorised into four levels and coded $0-3$. Although there was an overall agreement of $87.0 \%$, this was only slightly higher than the $84.1 \%$ agreement expected by chance, yielding a $\kappa$ of 0.18 . None of the nine jobs that were assigned a high level of formaldehyde was considered exposed to wood dust. Of the 11 jobs assigned to a high level of wood dust, nine were assigned to the low and two to the moderate category of exposure to formaldehyde.

\section{STATISTICAL ANALYSES}

The exposure assessments and job history were used to calculate the following sets of variables for formaldehyde and wood dust for each subject: ever exposed, maximum concentration exposed (three levels plus unexposed) over the lifetime, duration (years) exposed, and cumulative exposure, which was calculated as the product of the exposure concentration (using category midpoints) and the duration at that level summed across all jobs held. For formaldehyde, the exposure category midpoints used were $0.05,0.30$, and $0.75 \mathrm{ppm}$; for wood dust, they were $0.55,1.50$, and $6.0 \mathrm{mg} / \mathrm{m}^{3}$. Duration and cumulative exposure were also calculated after excluding any exposures during the most recent 10 years before the reference date (10 year lag). For formaldehyde, the exposure probability of each job was taken into account in calculating these variables. One set of variables (ever, maximum, duration, cumulative exposure) was calculated considering jobs with an exposure probability of possible or higher $(\geqslant 10 \%)$, another set was developed considering jobs only with probable or higher exposure, and another considering jobs only with definite exposure. For consistency, the referent group for analyses of formaldehyde always consisted of people considered unexposed in all jobs.

The distribution among cases and controls exposed to formaldehyde of duration in exposed jobs and cumulative exposure are described with quantile-quantile plots. $^{37} 38$ These are scatter plots of the exposure concentration for each case versus each control after sorting the observations into ascending order.

Odds ratios (ORs) and 95\% confidence intervals (95\% CIs) associated with potential occupational exposure to formaldehyde and wood dust were calculated with logistic regression, in which the potential confounding effects of other risk factors were taken into account as necessary, and the STATA (release 6) statistical package. ${ }^{37}$ We examined the following potential confounding factors: age, sex, race, SEER site, cigarette use, alcohol intake, and education. ${ }^{17}$ Modification by these factors of the relative risk estimates associated with formaldehyde and exposure to wood dust was assessed by calculating stratum specific ORs and by adding interaction terms to the logistic model. The effect of proxy interviews on the relative risk estimates was investigated by controlling for proxy status for certain analyses, and by restricting the analyses to direct interviews for others. These approaches yielded similar results, so only results based on controlling for proxy status are reported. When categories of duration and cumulative exposure were used, cut off points were based on the 50th and 75th percentile among exposed controls. Tests for trend were carried out with likelihood ratio tests associated with the addition of the variable of interest coded as $\log$ transformed continuous measures-for 
Table 2 Duration and concentration of occupational exposure to formaldehyde relative to risk of nasopharyngeal cancer by histological type

\begin{tabular}{|c|c|c|c|c|c|c|c|c|c|}
\hline \multirow[b]{3}{*}{$\begin{array}{l}\text { Exposure to } \\
\text { formaldehyde }\end{array}$} & \multirow{3}{*}{$\begin{array}{l}\text { Controls } \\
(n=244) \\
n\end{array}$} & \multicolumn{8}{|l|}{ Cases } \\
\hline & & \multicolumn{2}{|c|}{ All epithelial } & \multicolumn{2}{|c|}{$\begin{array}{l}\text { Undifferentiated and } \\
\text { non-keratinising }\end{array}$} & \multicolumn{2}{|c|}{ Differentiated squamous cell } & \multicolumn{2}{|c|}{ Epithelial } \\
\hline & & $\begin{array}{l}(n=196) \\
n\end{array}$ & ORt $(95 \% C I)$ & $\begin{array}{l}(n=54) \\
n\end{array}$ & OR† $(95 \% C I)$ & $\begin{array}{l}(n=118) \\
n\end{array}$ & OR† (95\% CI) & $\begin{array}{l}(n=24) \\
n\end{array}$ & $O R+(95 \% C I)$ \\
\hline Unexposed & 165 & 117 & 1.0 (reference) & 36 & 1.0 (reference) & 69 & 1.0 (reference) & 12 & 1.0 (reference) \\
\hline Ever exposed & 79 & 79 & $1.3(0.8$ to 2.1$)$ & 18 & $0.9(0.4$ to 2.0$)$ & 49 & $1.5(0.8$ to 2.7$)$ & 12 & $3.1(1.0$ to 9.6$)$ \\
\hline \multicolumn{10}{|c|}{ Maximum exposure (ppm): } \\
\hline$<0.10$ & 56 & 60 & $1.4(0.8$ to 2.4$)$ & 14 & $1.0(0.4$ to 2.4$)$ & 35 & $1.6(0.8$ to 3.0$)$ & 11 & $4.0(1.2$ to 13.1$)$ \\
\hline $0.10-0.50$ & 19 & 14 & $0.9(0.4$ to 2.3$)$ & 3 & $0.5(0.1$ to 3.1$)$ & 10 & $1.2(0.4$ to 3.3$)$ & 1 & $1.5(0.2$ to 13.9$)$ \\
\hline$>0.50$ & 4 & 5 & $1.6(0.3$ to 7.1$)$ & 1 & $1.5(0.2$ to 14.7$)$ & 4 & $2.1(0.4$ to 12.3$)$ & 0 & 0 \\
\hline Trend test & & & $\mathrm{p}=0.57$ & & $\mathrm{p}=0.72$ & & $\mathrm{p}=0.32$ & & $\mathrm{p}=0.46$ \\
\hline \multicolumn{10}{|l|}{ Duration (y): } \\
\hline $1-5$ & 41 & 24 & $0.8(0.4$ to 1.6$)$ & 8 & $0.7(0.3$ to 2.2$)$ & 12 & $0.8(0.3$ to 2.0$)$ & 4 & $2.0(0.4$ to 9.8$)$ \\
\hline $6-17$ & 19 & 26 & $1.6(0.7$ to 3.4$)$ & 6 & $1.0(0.2$ to 3.9$)$ & 17 & $1.8(0.7$ to 4.3$)$ & 3 & $4.0(0.9$ to 18.6$)$ \\
\hline $\begin{array}{l}\geqslant 18 \\
\text { Trend test }\end{array}$ & 19 & 29 & $\begin{array}{l}2.1(1.0 \text { to } 4.5) \\
p=0.070\end{array}$ & 4 & $\begin{array}{l}1.2(0.3 \text { to } 4.8) \\
\mathrm{p}=0.82\end{array}$ & 20 & $\begin{array}{l}2.5(1.1 \text { to } 5.9) \\
\mathrm{p}=0.033\end{array}$ & 5 & $\begin{array}{l}4.2(0.8 \text { to } 21.5) \\
\mathrm{p}=0.036\end{array}$ \\
\hline
\end{tabular}

${ }^{\star}$ Includes jobs with estimated probability of exposure of possible or higher.

tORs adjusted for age, sex, race, SEER site, cigarette use, proxy status and education. Confidence intervals (CI) in parentheses.

example, duration in years-because they fit the data as well or in most cases better than the untransformed measure.

\section{Results}

The mean age of interviewed cases of NPC was 54.3 years; $67.9 \%$ were men. As designed, the age and sex distribution of controls ( 55.2 years, $67.2 \%$ men) was similar to the cases. Among cases, $76.0 \%$ were white, $12.2 \%$ Asian, 9.7\% African American and 2.0\% native American. Controls were more likely to be white $(90.6 \%)$, with African Americans (8.6\%) making up most of the others. More detailed information on these and additional risk factors has been published previously. ${ }^{17}$

FORMALDEHYDE

Among the 196 cases, 79 (40.3\%) had ever worked in a job with potential exposure to formaldehyde (including jobs with exposure probabilities of possible or higher), compared with $79(32.4 \%)$ of 244 controls (table 2). The crude adjusted OR was 1.4 , which decreased to 1.3 (95\% CI 0.8 to 2.1 ) after adjustment for other risk factors (table 2). There was not a consistent association or trend in risk with maximum exposure concentration. The OR was modestly increased among those who had been exposed to higher concentrations (defined as $>0.50 \mathrm{ppm}$ ), but few subjects in the study had worked in such jobs. However, we

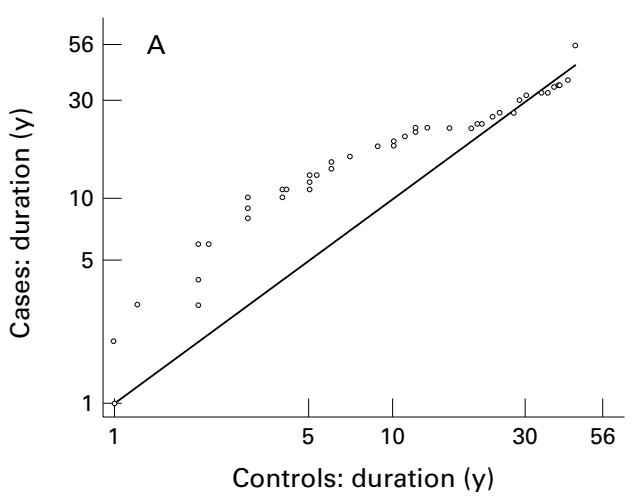

did find a trend of increasing risk with increasing duration of work in jobs with potential exposure (trend $\mathrm{p}=0.070$ ). The $\mathrm{OR}$ for those who had worked $\geqslant 18$ years in such jobs was $2.1(95 \% \mathrm{CI}=1.0$ to 4.5$)$.

We found evidence that the association between potential exposure to formaldehyde and risk of NPC was not homogeneous across histologies (table 2). There was no evidence of an association with undifferentiated and nonkeratinising tumours, whereas for differentiated squamous cell and epithelial NOS carcinomas, significant trends in risk were found with increasing duration of work in jobs exposed to formaldehyde.

More detailed analyses therefore focused on the group of 142 differentiated squamous cell and epithelial NOS carcinomas. Figure A describes the distribution of duration of exposure among cases and controls, and is based on jobs with exposure probabilities of possible and higher. This quantile-quantile plot was created by sorting the cases and controls into ascending order based on their duration of exposure, pairing observations of identical rank, and plotting the duration value of each case versus its paired control. ${ }^{38}$ Because controls outnumbered cases, the plotted points for the controls represent interpolated values. Overall, the distribution among exposed cases was shifted towards higher concentrations compared with controls, as indicated by points above the solid

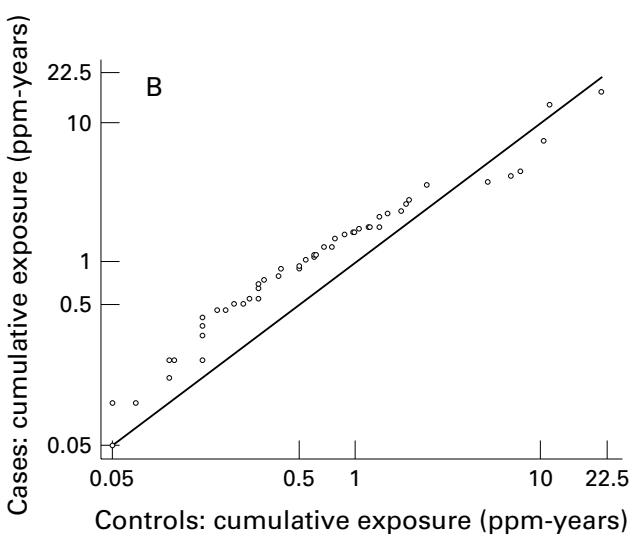

Quantile-quantile plots of the distribution among exposed cases and controls of $(A)$ duration of jobs exposed to formaldehyde and (B) cumulative exposure to formaldehyde. 
Table 3 Duration, cumulative exposure, and probability of occupational exposure to formaldehyde in relation to risk of nasopharyngeal cancert

\begin{tabular}{|c|c|c|c|c|c|c|c|c|c|}
\hline \multirow[b]{3}{*}{$\begin{array}{l}\text { Exposure to } \\
\text { formaldehyde }\end{array}$} & \multicolumn{9}{|c|}{ Probability of exposure } \\
\hline & \multicolumn{3}{|c|}{ Possible, probable or definite } & \multicolumn{3}{|c|}{ Probable or definite } & \multicolumn{3}{|l|}{ Definite } \\
\hline & $\begin{array}{l}\text { Controls } \\
n\end{array}$ & $\begin{array}{l}\text { Cases } \\
n\end{array}$ & $O R \ddagger(95 \% C I)$ & $\begin{array}{l}\text { Controls } \\
n\end{array}$ & $\begin{array}{l}\text { Cases } \\
n\end{array}$ & $O R \ddagger(95 \% C I)$ & $\begin{array}{l}\text { Controls } \\
n\end{array}$ & $\begin{array}{l}\text { Cases } \\
n\end{array}$ & $O R \ddagger(95 \% C I)$ \\
\hline Ever & 79 & 61 & $1.6(1.0$ to 2.8$)$ & 30 & 27 & $2.1(1.1$ to 4.2$)$ & 2 & 10 & $13.3^{\star}(2.5$ to 70$)$ \\
\hline \multicolumn{10}{|l|}{ Duration (y): } \\
\hline 1 to 5 & 41 & 16 & $0.9(0.4$ to 2.1$)$ & 17 & 12 & $2.0(0.8$ to 5.0$)$ & 1 & 5 & - \\
\hline 6 to 17 & 19 & 20 & $1.9(0.9$ to 4.4$)$ & 5 & 9 & $3.3(0.9$ to 11.8$)$ & 1 & 2 & - \\
\hline$>18$ & 19 & 25 & $2.7(1.2$ to 6.0$)$ & 8 & 6 & $1.6(0.5$ to 5.6$)$ & 0 & 3 & - \\
\hline Trend test & & & $\mathrm{p}=0.014$ & & & $\mathrm{p}=0.069$ & & & $\mathrm{p}<0.001$ \\
\hline \multicolumn{10}{|c|}{ Cumulative exposure (ppm-years): } \\
\hline $0.05-0.40$ & 40 & 15 & $0.9(0.4$ to 2.0$)$ & 16 & 12 & $1.9(0.7$ to 4.9$)$ & 1 & 4 & - \\
\hline$>0.4-1.10$ & 20 & 22 & $1.8(0.8$ to 4.1$)$ & 5 & 7 & $2.6(0.7$ to 9.5$)$ & 1 & 2 & - \\
\hline$>1.10$ & 19 & 24 & $3.0(1.3$ to 6.6$)$ & 9 & 8 & $2.2(0.7$ to 7.0$)$ & 0 & 4 & - \\
\hline Trend test & & & $\mathrm{p}=0.033$ & & & $\mathrm{p}=0.13$ & & & $\mathrm{p}<0.001$ \\
\hline
\end{tabular}

${ }^{\star} \mathrm{p}=.0007$, crude $\mathrm{OR}=10.2$, Fisher's exact test.

tExcluding undifferentiated and non-keratinising histologies.

‡ORs adjusted for age, sex, race, SEER site, cigarette use, proxy status, and education.

line. At the highest concentrations, however, they were similar, indicating that the distribution among controls was more skewed to the right. The mean durations among exposed cases and controls were 15.4 and 11.3 years respectively; the median durations were 13.0 and 5.0 years respectively. A similar pattern was evident for cumulative exposure (figure B). The mean cumulative exposure among exposed cases and controls was 0.9 and $0.4 \mathrm{ppm}-$ years respectively; the medians were 1.7 and 1.5 ppm-years respectively.

Table 3 describes the adjusted ORs relating duration and cumulative exposure to risk of NPC. These results illustrate the effects of taking into account the probability of exposure in each job. The OR associated with ever holding a job judged to involve possible, probable, or definite exposure to formaldehyde was 1.6 (95\% CI 1.0 to 2.8 ). This association was stronger when analyses focused on jobs with higher probabilities of exposure to formaldehyde. Among subjects ever holding a job judged probably exposed (or higher) the OR was 2.1 (95\% CI 1.1 to 4.2 ). Of the 12 people who had ever held jobs considered definitely exposed, 10 were cases, yielding an OR of 13.3 ( $95 \%$ CI 3.4 to 70 ). These 10 cases held a total of 14 jobs with definite exposures and an additional 12 with probable or possible exposures. The two controls held three jobs with definite exposures and none with lower probabilities. For the 10 cases, examples of some of the jobs and activities that were assigned definite exposures include: chemical manufacturing with formaldehyde as a raw material (moderate), off-bearing from the saw and stacking of fibreboard in a fibreboard manufacturing plant (moderate), supervising the plating process in car manufacturing (moderate), off-bearing from a mill saw and sanding plywood in a plywood manufacturing plant (moderate), working as a barber and hairdresser (low), carpentry working on residential building and renovations (low), and working as a scrub nurse and handling biopsy specimens (low).

Significant exposure-response relations were found between risk of NPC and duration of exposure to formaldehyde as well as cumulative exposure when jobs with possible or higher probability of exposure were considered. The
OR associated with a duration $>18$ years of exposure was 2.7 (95\% CI 1.2 to 6.0 ), and with a cumulative exposure $>1.10$ ppm-year was 3.0 (95\% CI 1.3 to 6.6 ). When jobs with probable or definite probabilities were considered, the trends were less evident. However, when only jobs with definite exposures were examined, highly significant $(p<0.001)$ trends in risk of NPC with increasing duration and cumulative exposure were found. The relatively few subjects with definite exposure precluded the estimation of meaningful ORs by specific concentration of exposure.

These analyses were also carried out taking into account a 10 year lag period. The individual results and the overall conclusions were similar (data not shown).

We found evidence that suggested that the association between risk of NPC and potential exposure to formaldehyde was stronger among cigarette smokers. Among current and former smokers, the OR associated with ever working in a job exposed to formaldehyde (including jobs with possible or higher probabilities) was 2.3 (95\% CI 1.3 to 4.2 ), compared with OR 0.5 (95\% CI 0.2 to 1.8$)$ among never smokers (test for homogeneity $\mathrm{p}=0.024$ ). Similarly, when continuous measures were examined, a significant trend $(\mathrm{p}=0.003)$ was found between risk of NPC and the cumulative exposure to formaldehyde among smokers, whereas no association was found in non-smokers. There was less statistical evidence for effect modification by age, where a higher relative risk estimate was found among younger subjects (test for homogeneity $\mathrm{p}=0.11$ ), and no evidence for variation in relative risk estimates by sex or SEER site.

The ORs for formaldehyde were essentially unaffected by adding exposure to wood dust to the models. For example, the OR associated with ever exposure to formaldehyde at a possible or higher probability cut off point was unchanged at 1.6 , and the OR at a probable or higher cut off point increased from 2.1 to 2.2. The coefficients for the continuous measures of formaldehyde were similarly unchanged.

WOOD DUST

Among the 196 cases of carcinoma of any histological type, $22(11.2 \%)$ had worked in jobs 
Table 4 Wood dust exposure concentration, duration and cumulative exposure relative to risk of nasopharyngeal cancer*

\begin{tabular}{|c|c|c|c|c|}
\hline \multirow[b]{2}{*}{ Exposure to wood dust } & \multirow{2}{*}{$\begin{array}{l}\text { Controls } \\
(n=244) \\
n\end{array}$} & \multirow{2}{*}{$\begin{array}{l}\text { Cases } \\
(n=142) \\
n\end{array}$} & \multicolumn{2}{|c|}{ Adjusted for formaldehyde } \\
\hline & & & $\begin{array}{l}\text { No ORt } \\
(95 \% C I)\end{array}$ & $\begin{array}{l}\text { Yes OR } \\
(95 \% C I)\end{array}$ \\
\hline Unexposed & 220 & 125 & 1.0 (reference) & 1.0 (reference) \\
\hline Ever exposed & 24 & 17 & $1.5(0.7$ to 3.3$)$ & $1.2(0.5$ to 2.7$)$ \\
\hline \multicolumn{5}{|c|}{ Maximum exposure $\left(\mathrm{mg} / \mathrm{m}^{3}\right)$ : } \\
\hline$>0.0-0.55$ & 15 & 10 & $1.7(0.7$ to 4.4$)$ & $1.3(0.5$ to 3.6$)$ \\
\hline$>0.55-1.50$ & 4 & 6 & $2.5(0.6$ to 10.2$)$ & $2.0(0.5$ to 8.1$)$ \\
\hline$>1.50$ & 5 & 1 & $0.3(0.0$ to 3.2$)$ & $0.2(0.0$ to 2.1$)$ \\
\hline Trend test & & & $\mathrm{p}=0.76$ & $\mathrm{p}=0.68$ \\
\hline \multicolumn{5}{|l|}{ Duration (y): } \\
\hline $1-4$ & 12 & 8 & $1.5(0.5$ to 4.2$)$ & $1.4(0.5$ to 4.4$)$ \\
\hline $5-13$ & 6 & 4 & $1.4(0.3$ to 5.6$)$ & $1.3(0.3$ to 5.4$)$ \\
\hline$\geqslant 14$ & 6 & 5 & $1.8(0.5$ to 7.3$)$ & $0.8(0.2$ to 3.7$)$ \\
\hline Trend test & & & $\mathrm{p}=0.27$ & $\mathrm{p}=0.74$ \\
\hline \multicolumn{5}{|c|}{ Cumulative exposure ( $\mathrm{mg} / \mathrm{m}^{3}$-years): } \\
\hline$>0.0-2.75$ & 13 & 5 & $0.9(0.3$ to 3.0$)$ & $0.7(0.2$ to 2.5$)$ \\
\hline$>2.75-15.70$ & 5 & 10 & $3.9(1.2$ to 12.5$)$ & $3.0(0.9$ to 9.8$)$ \\
\hline$>15.70$ & 6 & 2 & $0.6(0.1$ to 3.7$)$ & $0.4(0.1$ to 2.3$)$ \\
\hline Trend test & & & $\mathrm{p}=0.42$ & $\mathrm{p}=0.99$ \\
\hline
\end{tabular}

${ }^{\star}$ Excluding undifferentiated and non-keratinising histologies.

†OR adjusted for age, sex, race, SEER site, cigarette use, proxy status, and education.

$\ddagger \mathrm{OR}$ also adjusted for cumulative exposure to formaldehyde with the log transformed continuous measure and including jobs with possible or higher probabilities of exposure.

judged to entail exposure to wood dust, compared with $24(9.8 \%)$ controls. The crude OR of 1.2 increased to 1.3 (95\% CI 0.6 to 2.6 ) after controlling for age, sex, race, education, SEER site, proxy status, and cigarette use. Additional control for cumulative exposure to formaldehyde reduced the OR to 1.1 (95\% CI 0.5 to 2.3 )

Further analyses of exposure to wood dust focused on the 142 cases of NPC remaining after excluding those with undifferentiated and non-keratinising histologies (table 4). After adjusting for the main risk factors (but not formaldehyde), there was only weak evidence of an association with ever working in a job with potential exposure (OR $1.5 ; 95 \%$ CI 0.7 to 3.3). There was also little evidence of a trend of increasing risk with maximum exposure concentration, duration in jobs exposed to wood dust, or cumulative exposure. The modest associations that were found were further reduced in strength after controlling for potential exposure to formaldehyde (table 4). There was no evidence of an association between NPC and wood dust among subgroups defined by age, sex, SEER site, cigarette use, or exposure to formaldehyde.

\section{Discussion}

In this multicentre, population based casecontrol study we found an increased risk of NPC associated with potential occupational exposure to formaldehyde, but not wood dust. The associations with formaldehyde were specific to histological types other than nonkeratinising and undifferentiated. This is consistent with several lines of evidence suggesting a different constellation of inherited and environmental risk factors for the different histological types. In particular, the distribution of histologies varies markedly according to the underlying incidences in a population; the non-keratinising and undifferentiated types comprise most of the cases in high incidence populations - such as Chinese and Filipinoswhereas squamous cell carcinomas make up over two thirds of carcinomas occurring in white people in the United States. ${ }^{16}$ Also, the Epstein-Barr virus (EBV) seems to play a more important part in non-keratinising and undifferentiated carcinomas. ${ }^{39}$ Finally, a previous report from this study suggested a stronger role for cigarette smoking in the aetiology of squamous cell carcinomas. ${ }^{17}$ If occupational exposure to formaldehyde is a causal factor, we estimate that such exposure accounts for about $16 \%$ of squamous cell and unspecified carcinomas of the nasopharynx in the United States.

\section{STUDY DESIGN}

There are several notable strengths to this study. It is the largest interview based study of NPC conducted to date in the United States, and the largest such study world wide that has focused on occupational exposures. It is population based and includes incident, rather than fatal, cancers. Evaluation of the role of formaldehyde and wood dust in the aetiology of NPC was the primary aim of the study. Trained interviewers collected detailed information on lifetime jobs, activities on those jobs, and self reported exposures. Exposure assessment for formaldehyde and wood dust was carried out by industrial hygienists with substantial experience in assessing such exposures in epidemiological studies. The availability of histological information from the SEER registries allowed investigation of associations specific to certain histological types. Finally, the availability of detailed information on the major risk factors for NPC allowed control for their potential confounding effects, as well as exploration of their possible interactions with formaldehyde and wood dust.

Several limitations should also be considered in interpreting these results. Most importantly, the actual exposure to formaldehyde and wood dust was not measured. We relied on self reported occupational histories, and assessed the probability and likely concentration of exposure in each job with exposure measurements from industry based studies, supplemented by personal experience. Such assessment is challenging in a community based study, particularly in the absence of information about working conditions-such as enclosures, ventilation, duration of certain tasks, and use of specific personal protective equipment. Thus misclassification of exposure was inevitable in this study. However, given that exposure assessment of reported jobs was carried out without knowledge of case status, and that subjects reported occupational histories without specific knowledge of the hypotheses under consideration, exposure misclassification was likely to be similar for cases and controls. In most, although not all circumstances, such non-differential misclassification will introduce a conservative bias. ${ }^{40} 41$

The possibility exists that the associations found with potential exposure to formaldehyde are attributable to other, unmeasured risk factors correlated with work in jobs exposed to formaldehyde. The diversity of jobs considered to be exposed, however, argues against a correlated occupational exposure. Uncontrolled or 
residual confounding from lifestyle factors may still exist, but is also unlikely. To the extent that the cases and controls with completed interviews are not representative of their target populations for the exposures of interest, the results also may be biased. We previously examined the characteristics of noninterviewed cases in this study, and did not find striking differences compared with interviewed cases. ${ }^{17}$ Although non-interviewed cases were more likely to have distant stage of disease at diagnosis $(35.2 \% v 22.5 \%)$, they were similar in age and histology, and only slightly more likely to be female and of the black or Asian race. No information was available on characteristics of non-interviewed controls, thus the direction and magnitude of any response bias is difficult to predict.

Another limitation was that interviews with proxy respondents were necessary for $19.0 \%$ of cases, but only $1.2 \%$ of controls. In general, proxies report fewer jobs than index subjects, especially in the more distant past. ${ }^{42-44}$ To the extent that such jobs entailed exposure to formaldehyde and wood dust, and that exposures in the more distant past are aetiologically relevant, this also would result in a conservative bias if not considered in the analyses. However, results were little changed when proxy interviews were excluded and when we adjusted for proxy status in analyses, suggesting that this was not an important limitation.

PREVIOUS STUDIES OF FORMALDEHYDE

Several previous studies have suggested a link between occupational exposure to formaldehyde and risk of NPC. In the largest reported historical cohort mortality study, which was conducted among 26561 employees of 10 factories that used or produced formaldehyde, six cases of NPC were found compared with two expected, yielding a non-significant relative risk estimate (based on standardised mortality ratio (SMR)) of 3.0. ${ }^{2}$ There was no evidence of an exposure-response relation in the overall data. However, further analyses showed a nonsignificant trend of increasing risk among people exposed to particulates; the relative risk estimates were $1.9,4.0$, and 7.5 in workers exposed to $<0.5$ ppm-years, $0.5-<5.5$ ppmyears and $\geqslant 5.5$ ppm-years respectively. ${ }^{45}$ This finding is notable in the light of the results from the current study in which the association between exposure to formaldehyde and risk of NPC was stronger among cigarette smokers (who are also exposed to particulates). Further follow up of workers at one chemical plant where four of the cases were, showed no additional cases of NPC (SMR 5.5, p<0.05) beyond those included in the earlier analyses. ${ }^{46}$

A proportional mortality study of 4046 deaths among embalmers and funeral directors also reported increased risk of NPC, with a relative risk estimate of 2.2 (95\% CI 0.6 to 5.5). ${ }^{3}$ By contrast, in the only other relatively large cohort study reported, which included 14017 workers in the British chemical industry, no cases of NPC were found compared with 1.3 expected. ${ }^{8}$ The upper $95 \%$ CI of the SMR was not provided, but can be calculated to be 2.8. Although several other cohort studies of workers exposed to formaldehyde have found no cases of NPC, or did not report on NPC, all had very small expected numbers of NPC deaths (less than one) (reviewed by Collins et al). ${ }^{47}$

A previous population based case-control study conducted in western Washington also found a suggestion of increased risk among workers exposed to formaldehyde. ${ }^{4}$ This study was based on 27 cases of all histological types. Exposures in this study were assessed with a job exposure matrix developed for the study. The OR among people employed $\geqslant 10$ years in a job potentially involving exposure to formaldehyde was 1.6 (95\% CI 0.4 to 5.8). An exposure score was calculated which combined duration, likelihood, and intensity of exposure; the OR associated with the highest exposure score was 2.1 (95\% CI 0.6 to 7.8 ). In this same study, an increased risk of NPC was found among people potentially exposed to formaldehyde from residing in mobile (manufactured) homes for $\geqslant 10$ years (OR 5.5, 95\% CI 1.6 to 19.4). ${ }^{48}$

Two additional case-control studies reported similar results. In the first, a case-control study based on cancer registry and death certificates of 173 cases of NPC in Connecticut, people with probable occupational exposures to high concentrations of formaldehyde for $\geqslant 20$ years before death had a 2.3 -fold increase $(95 \%$ CI 0.9 to 6.0 ) in risk compared with people who were never exposed. ${ }^{5}$ From a hospital based case-control study of 108 cases of NPC in the Philippines, West et al, reported a 2.1 -fold increase (95\% CI 0.7 to 6.2 ) among people judged to be occupationally exposed to formaldehyde for $\geqslant 15$ years when a 10 year lag time was taken into account. ${ }^{6}$ However, in a Danish study of 314 cases of NPC, which linked data on incident cancers with employment histories, an increased risk with exposure to formaldehyde was found among women (OR 2.6, 95\% CI 0.3 to 21.9 ) but not men (OR $0.7,95 \%$ CI 0.3 to 1.7$){ }^{9}$

Strengths of these industry based cohort studies include presumably a more accurate assessment of exposure to formaldehyde, and a higher proportion of subjects with high exposures compared with those case-control studies that were community based. However, the cohort studies have weaknesses as well. In particular, each was limited in statistical power to detect an association due to both the low incidence of NPC and the relatively high survival $\left(30 \%-50 \%\right.$ at 5 years). ${ }^{16}$ In studies of cancers - such as NPC - for which a substantial proportion of people can experience long term survival, the possibility of bias due to differential case fatality should also be considered. ${ }^{49}$ None of the studies already mentioned was able to control for major risk factors for the disease, in particular cigarette smoking, with the exception of the small study in western Washington. Finally, none of the previous studies was able to examine associations with specific histology. A previous report from the current study found very different risk factor profiles for NPC by histological type. ${ }^{17}$ In 
particular, cigarette smoking and alcohol use were important risk factors for differentiated squamous cell carcinomas, but unrelated to undifferentiated and non-keratinising carcinomas. The results for formaldehyde followed the same pattern. If formaldehyde is truly associated only with squamous cell carcinomas, then relative risk estimates from studies of NPC which did not take into account histological type would be attenuated.

PREVIOUS STUDIES OF WOOD DUST

Studies of wood dust in the aetiology of NPC are more limited. Data from the previous study of 27 cases of NPC in western Washington showed little overall association with work in occupations entailing exposure to wood dust (adjusted OR $1.2,95 \%$ CI 0.2 to 4.6$).{ }^{12}$ This association was strengthened, but remained non-significant, when limited to long term $(\geqslant 10$ years) employment in the more distant past (OR $4.2,95 \%$ CI 0.4 to 26.6). In a 1995 IARC report that reviewed this and other casecontrol studies relating risk of NPC in humans to work in occupations related to exposure to wood or to wood dust, the working group concluded that whereas there was substantial evidence linking exposure to wood dust to adenocarcinoma of the sinonasal cavity, the evidence for increased risk of NPC was only suggestive. ${ }^{150} 51$

Subsequent to this review, Demers et $a l^{1452}$ reported results from a pooled reanalysis of cancer mortality among 28704 workers in the furniture, plywood, and wood modelling industries. Overall they found a significantly increased risk of NPC (SMR 2.4; 95\% CI $=1.1$ to 4.5) based on nine observed cases. Among those definitely exposed, the SMR was 5.3 (95\% CI 1.7 to 12.4 ). Strengths of this pooled analysis include many subjects who had relatively high exposures, although it was limited by a lack of information on histology and potential risk factors-such as cigarette use and exposure to formaldehyde.

\section{Conclusions}

Results from this study support the hypothesis that occupational exposure to formaldehyde increases risk of NPC. This association seems to be specific to squamous cell carcinomas, as there was no evidence of an association with undifferentiated and non-keratinising carcinomas. By contrast, our results are not consistent with suggestive evidence linking occupational exposure to wood dust and risk of NPC. Established cohorts of workers exposed to formaldehyde and wood dust should continue to be monitored for NPC and other respiratory cancers. Also, we recommend that future studies of NPC take into account histological type in assessing risk from environmental and host factors. This research was supported in part by NCI grants R29 CA 46552 and R03 CA50256, and NCI contract N01 CN67009.

\footnotetext{
1 International Agency for Research on Cancer Working Group. Wood dust and formaldehyde. IARC monographs on the
evaluation of the carcinogenic risk of chemicals to humans. Vol evaluation of the carcinogenic risk
}

2 Blair A, Stewart P, O'Berg M, et al. Mortality among industrial workers exposed to formaldehyde. $\mathcal{F}$ Natl Cancer Inst trial workers exposed

3 Hayes RB, Blair A, Stewart PA, et al. Mortality of US embalmers and funeral directors. Am f Ind Med 1990;18: $641-52$

4 Vaughan TL, Strader C, Davis S, et al. Formaldehyde and cancers of the pharynx, sinus and nasal cavity: I Occupational exposures. Int f Cancer 1986;38:677-83.

5 Roush GC, Walrath J, Stayner LT, et al. Nasopharyngeal cancer, sinonasal cancer, and occupations related to formaldehyde: a case-control study. $\mathcal{F}$ Natl Cancer Inst 1987;79:1221-4

6 West S, Hildesheim A, Dosemeci M. Non-viral risk factors for nasopharyngeal carcinoma in the Philippines: results from a case-control study. Int f Cancer 1993;55:722-7.

7 Walrath J, Fraumeni Jr JF. Mortality patterns among embalmers. Int f Cancer 1983;31:407-11.

8 Gardner MJ, Pannett B, Winter PD, et al. A cohort study of workers exposed to formaldehyde in the British chemical industry: an update. $\mathrm{Br}$ F Ind Med 1993;50:827-34.

9 Olsen JH, Jensen SP, Hunk M, et al. Occupational formaldehyde exposure and increased nasal cancer risk in man. Int f Cancer 1984;34:639-44.

10 Acheson ED, Cowdell RH, Hadfield E, et al. Nasal cancer in woodworkers in the furniture industry. BMF 1968;ii:587-

11 Leclerc A, Martinez Cortes M, Gerin M, et al. Sinonasal cancer and wood dust exposure: results from a case-control study. Am F Epidemiol 1994;140:340-9.

12 Vaughan TL, Davis S. Wood dust exposure and squamous cell cancers of the upper respiratory tract. $A m \mathcal{F}$ Epidemiol 1991;133:560-4.

13 Demers PA, Kogevinas M, Boffetta P, et al. Wood dust and sino-nasal cancer: pooled reanalysis of twelve case-control studies. Am F Ind Med 1995;28:151-66.

14 Demers PA, Boffetta P. Cancer risk from occupational exposure to wood dust: a pooled analysis of epidemiological studies. Lyon, France: International Agency for Research on Cancer, France: International Agency for Res

15 Blair A, Kazerouni N. Reactive chemicals and cancer. Cancer Causes Control 1997;8:473-90.

16 Burt RD, Vaughan TL, McKnight B. Descriptive epidemiology and survival analysis of nasopharyngeal carcinoma in the United States. Int $\mathcal{F}$ Cancer 1992;52:549-56.

17 Vaughan TL, Shapiro JA, Burt RD, et al. Nasopharyngeal cancer in a low-risk population: defining risk factors by histologic type. Cancer Epidem Biomarkers Prev 1996;5:58793.

18 Waksberg J. Sampling methods for random digit dialing. Fournal of the American Statistical Association 1978;73:40-6.

19 Shanmugaratnam K, Sobin L. Histological typing of upper respiratory tract tumors. International histological typing of piratory tract tumors. International histological typing of

20 Stewart PA, Blair A, Cubit DA, et al. Estimating historical exposures to formaldehyde in a retrospective mortality study. Appl Ind Hyg 1986;1:34-41.

21 Stewart PA, Herrick RF, Feigley CE, et al. Study design for assessing exposures of embalmers for a case-control study. Part I. Monitoring results. Appl Occup Environ Hyg 1992;7: 532-40.

22 Teschke K, Hertzman C, Morrison B. Level and distribution of employee exposures to total and respirable wood dust in two Canadian sawmills. Am Ind Hyg Assoc $\mathcal{F} 1994$; 55:245-50.

23 Teschke K, Demers PA, Davies HW, et al. Determinants of exposure to inhalable particulate, wood dust, resin acids, and monoterpenes in a lumber mill environment. Ann accup Hyg 1999;43:247-55.

24 Teschke K, Marion SA, Vaughan TL, et al. Exposures to wood dust in US industries and occupations, 1979-97. Am wood dust in US industries and
Ind Hyg Assoc F 1999;35:581-9.

25 Virtamo $M$, Tossavainen: gases formed from furan binding agents. Scand $\mathcal{F}$ Work Environ Health 1976;2(suppl I):50-3.

26 Stroup N. Identification of industries that used or manufactured formaldehyde. Bethesda, MD: Report prepared for the National Cancer Institute (unpublished), 1982.

27 McGuire MT, Casserly DM, Greff RM. Formaldehyde concentrations in fabric stores. Appl Occup Environ Hyg 1992;7:112-19.

28 Flyvholm M-A, Andersen P. Identification of formaldehyde releasers and occurrence of formaldehyde and formaldehyde releasers in registered chemical products. Am f Ind Med 1993;24:533-52.

29 Hamill A, Ingle J, Searle S, et al. Levels of exposure to wood dust. Ann Occup Hyg 1991;35:397-403.

30 Holliday MG, Dranitsaris P, Strahlendorf PW, et al. Wood dust exposure in Ontario industry: the occupational health aspects. Vol 2. Ottawa, Ontario: Michael Holliday, 1986.

31 Jones PA, Smith LC. Personal exposures to wood dust of woodworkers in the furniture industry in the High Wycombe area: a statistical comparison of 1983 and 1976-7 survey results. Ann Occup Hyg 1986;30:171-84.

32 Mazurkiewicz M, Festa JL. Wood dust exposure in US plants. Wood and Wood Products 1989;94:159-62.

33 McCammon CS, Robinson C, Waxweiler RJ, et al. Industrial hygiene characterization of automotive wood model shops. Am Ind Hyg Assoc 7 1985;46:343-9.

34 Sass-Kortsak AM, Holness DL, Pilger CW, et al. Wood dust and formaldehyde exposures in the cabinet-making industry. Am Ind Hyg Assoc f 1986;47:747-53.

35 Teschke K, Hertzman C, Morrison B. Level and distribution of employee exposures to total and respirable wood 
dust in two Canadian sawmills. Am Ind Hyg Assoc 7 1994; 55:245-50

36 Whitehead LW, Freund T, Hahn LL. Suspended dust concentrations and size distribution and quantitative analysis of inorganic particles from woodworking operations. Am Ind Hyg Assoc F 1981;42:461-7.

37 Stata. Stata Statistical Software: Release 6.0. College Station, TX: Stata, 1999

38 Chambers JM, Cleveland WS, Kleiner B, et al. Graphical methods for data analysis. Belmont, CA: Wadsworth, 1983.

39 Nicholls JM, Agathanggelou A, Fung K, et al. The association of squamous cell carcinomas of the nasopharynx with Epstein-Barr virus shows geographical variation reminiscent of Burkitt's lymphoma. 7 Pathol 1997;183:164-8.

40 Thomas DC. When will non-differential misclassification of an exposure preserve the direction of a trend. Am 7 Epidemiol $1995 ; 142: 782-3$.

41 Birkett NJ. Effect of non-differential misclassification on Am ₹ Epidemiol 1992;136:356-62. Am f Epidemiol 1992;136:356-62.

Lerchen ML, Samet JM. An assessment of the validity of questionnaire responses provided by a surviving spouse. Am f Epidemiol 1986;123:481-9.

43 Shalat SL, Christiani DC, Baker EL. Accuracy of work history obtained from a spouse. Scand $\mathcal{F}$ Work Environ Health 1987;13:67-9.

44 Vaughan TL. Occupation and squamous cell cancers of the pharynx and sinonasal cavity. Am F Ind Med 1989;16:493 510 .
45 Blair A, Stewart PA, Hoover RN, et al. Cancers of the nasopharynx and oropharynx and formaldehyde exposure. Natl Cancer Inst 1987;78:191.

46 Marsh GM, Stone RA, Esmen NA, et al. Mortality among chemical workers in a factory where formaldehyde was used. Occup Environ Med 1996;53:613-27.

47 Collins JJ, Acquavella JF, Esmen NA. An updated meta-analysis of formaldehyde exposure and upper respiratory tract cancers. F Occup Environ Med 1997;39:639-51.

48 Vaughan TL, Strader C, Davis S, et al. Formaldehyde and cancers of the pharynx, sinus and nasal cavity: II. Residential exposures. Int $\mathcal{f}$ Cancer 1986;38:685-8.

49 Demers PA, Vaughan TL, Checkoway H, et al. Cancer identification using a tumor registry versus death certificates in occupational cohort studies in the United States. Am F Epidemiol 1992;136:1232-40.

50 Kawachi I, Pearce N, Fraser J. A New Zealand cancer registry-based study of cancer in wood workers. Cancer 1989;64:2609-13.

51 Sriamporn S, Vatanasapt V, Pisani P, et al. Environmental risk factors for nasopharyngeal carcinoma: a case-control study in northeastern Thailand. Cancer Epidemiol Biomarkers Prev 1992;1:345-8.

52 Demers PA, Boffetta P, Kogevinas M, et al. Pooled reanalysis of cancer mortality among five cohorts of workers in wood-related industries. Scand $\mathcal{f}$ Work Environ Health 1995;21:179-90. 